\title{
IMMUNOHISTOCHEMICAL EXPRESSION OF TLR-4 AND ITS CORRELATION TO VARIOUS GRADES OF ORAL SQUAMOUS CELL CARCINOMA
}

\author{
Enas M. Omar ${ }^{1} M S c$, Taissir A. Omar ${ }^{2} P h D$, Sahar M. El-Sheikh ${ }^{2} P h D$, Sahar E. \\ $\operatorname{Riad}^{2} P h D$, Ghada M. Mourad ${ }^{3} P h D$, Marwa M. Afifi ${ }^{4} P h D$
}

\begin{abstract}
INTRODUCTION: Oral cancer is a major health problem, causing high morbidity and mortality rates. Oral squamous cell carcinoma (OSCC) accounts for $90-95 \%$ of all oral malignancies. During the last decade, significant evidence has suggested that inflammation plays an important role in tumorigenesis, and microenvironment-derived signals which are important constituents in all tumors. Toll-like receptors (TLRs) are classical signals that play a key role in the innate immune system. They drive the inflammatory response and control the cellular proliferation and survival by stimulating the immune cells and promoting integrated processes of inflammation and tissue repair. This can predict that TLR4 may be of great significance in tumors. Hence, this study is to evaluate and correlate the expression of TLR-4 in various grades of oral squamous cell carcinoma (OSCC).

OBJECTIVES: To evaluate and correlate the expression of TLR-4 in different histopathological grades of OSCC

MATERIALS AND METHODS: An immunohistochemical (IHC) study using the TLR-4 antibody were done on 50 surgical specimens and 10 normal mucosal tissues taken from OSCC patients and healthy individuals, respectively. The staining were performed using a Labeled Strept-Avidin Biotin complex method (LSAB)

RESULTS: TLR-4 was expressed in human OSCC biopsies and the expression level was correlated with the tumor differentiation. Higher expression was detected in the well and the moderately differentiated squamous cell carcinomas than the poorly differentiated ones. CONCLUSIONS: TLR-4 expression could be a prognostic factor in oral squamous cell carcinoma cases as expression was detected in the well and moderately differentiated higher than poorly differentiated squamous cell carcinomas. KEYWORDS: Oral squamous cell carcinoma, TLR-4
\end{abstract}

1. Master in Oral Pathology Department, Faculty of Dentistry, Alexandria University.

2. Professor in Oral Pathology Department, Faculty of Dentistry, Alexandria University.

3 Professor in Histology and Cell Biology Department, Faculty of Medicine, Alexandria University.

4 Lecturer in Oral Pathology Department, Faculty of Dentistry, Alexandria University.

Corresponding author

E-mail: inas.magdy@gmail.com

\section{INTRODUCTION}

Cancer of the oral cavity and oropharynx is a global health burden with an estimated overall annual incidence of nearly 443,000 new cases and 241,450 deaths worldwide (1). The frequency of cancer in the middle east and north African (MENA) countries is increasing. It is currently considered the fourth leading cause of death after the cardiovascular, infectious, parasitic diseases, and finally traumatic injuries. More than 270,000 approximately die from cancer each year in this geographic area (2).

Oral squamous cell carcinoma (OSCC), represents the most frequent oral neoplasm and counts for more than $90 \%$ of oral cancer (3). Toll-like receptors (TLRs) belong to the class of pattern recognition receptors and are the first line of defense from invading pathogens. TLRs recognize pathogen-associated molecular patterns (PAMPs), which activate inflammation and the innate immunity response (4). Humans express ten functional TLRs (TLR1 to TLR10). TLR phenotypes, such as TLR2, TLR3, TLR4, TLR5, TLR7 and TLR 9, are expressed in various head and neck squamous cell carcinomas in vivo and in vitro $(5,6)$. TLR4 is well-known for recognizing lipopolysaccharide (LPS), which is a component present in many Gram-negative bacteria. TLR-4 activation results in the production of proinflammatory cytokines, through the myeloid differentiation primary response protein 88 (MyD88) dependent pathway, and the production of type 1 interferons, through a MyD88-independent pathway. TLR4 constitutes an important part of the innate immunity as it is the first line of host defense. It is expressed in the normal epithelial, immune and cancer cells (7).

Despite the favorable immune responses from TLR-4 expression, it appears to be a double-edged sword in cancers and has been related to both cancer inhibition and growth (8). Recently there is an increasing evidence that suggests the significance of TLRs and their ligands in many pathological conditions (9). Although there have been many reports on TLR-4 expression in different carcinomas, so far little, is known about its pathological significance in OSCC. However, targeting TLRs is now an exciting field for translational cancer research. In fact, to the best of our knowledge this is the first study to evaluate the expression of TLR-4 in OSCC cases in Egypt. The aim of the present work is to evaluate and correlate TLR-4 expression in the different OSCC histopathological grades. 


\section{MATERIALS AND METHODS}

Fifty cases of OSCC were obtained from the bio-archiving bank at Oral Pathology Department, Faculty of Dentistry, Alexandria University, Egypt. The diagnosis of the biopsies was confirmed histopathologically in the Oral Pathology Department at the Faculty of Dentistry, Alexandria University. In addition, 10 specimens were taken from the normal oral mucosa of patients who were indicated for alveoloplasty served as a control group. The biopsies of the patients and bio-archiving were in compliance to the Code of Professional Ethics for Dentistry adopted by the Alexandria University, Faculty of Dentistry.

The specimens were fixed in 10\% neutral buffered formalin, processed and embedded in paraffin wax using the conventional procedures. Serial sections of 3-4 $\mu \mathrm{m}$ thickness were placed on glass slides and stained using Hematoxylin and Eosin (H\&E) for confirmation. Immunohistochemical (IHC) staining using the TLR-4 antibody (Thermofisher, USA) was also performed using the Labeled Strept- Avidin Biotin complex method (LSAB) (10). The immunostaining results were scored using an image analyzer (Image J software).

Statistical Analysis (11):

The data were fed to the computer and analyzed using IBM SPSS software package version 20.0. (Armonk, NY: IBM Corp) (12). The Kolmogorov-Smirnov test was used to verify the normality of distribution. Quantitative data were described using range (minimum and maximum), mean, standard deviation and median. In all our statistical results, a $\mathrm{p}$ value $<0.05$ was considered significant. The $\mathbf{F}$-test (ANOVA) was used for normally distributed quantitative variables, to compare between more than two groups, while the Post Hoc test (Tukey) was used for pairwise comparisons.

\section{RESULTS}

\section{Clinical Results}

The demographic data of the patients included in the current study showed that: The age of the patients ranged from (4481 years). The mean age was found to be (61 years) while the median age was (59.5 years). Thirty-two patients (64\%) were females and eighteen (36\%) were males.

The most common site of occurrence was the lateral side of the tongue (52\%). This is followed by the buccal mucosa representing (18\%) and the alveolar mucosa $\mathbf{( 1 2 \% ) . ~ O t h e r ~}$ sites included in the present work were the retromolar area, the palate and the floor of the mouth which accounted for (6\%) each.

\section{Histopathological Results}

The microscopical examination of OSCC revealed that (22\%) were of the well differentiated type, $(\mathbf{6 4 \% )}$ were moderately differentiated, (14\%) were of the poorly differentiated type.

\section{Immunohistochemical Results}

All the cases of normal oral mucosa showed immunoreactivity to TLR-4. It was mainly detected in the basal and parabasal cell layers (Figure 1).

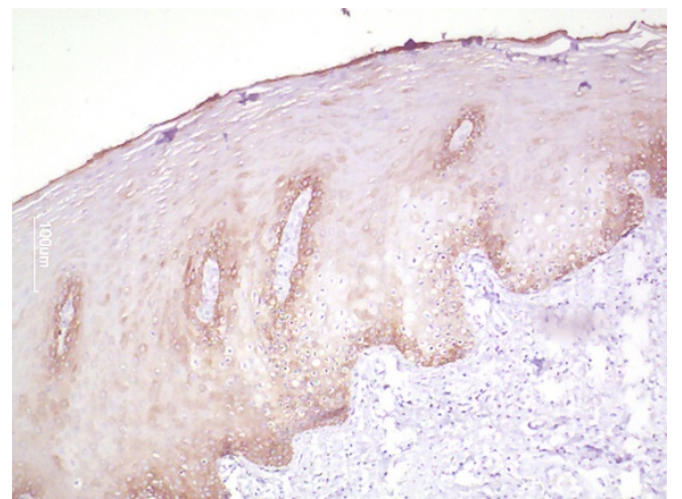

Figure 1: Normal Mucosa showing Positive Immunostaining of TLR-4 in The Basal and Para Basal Cell layers (x200).

All the included OSCC cases showed immunoreactivity to TLR-4 antibody:

The well differentiated OSCC showed diffuse positive cytoplasmic immunosignals of TLR-4 in the malignant epithelial cells forming the keratin pearls, (Figure 2).

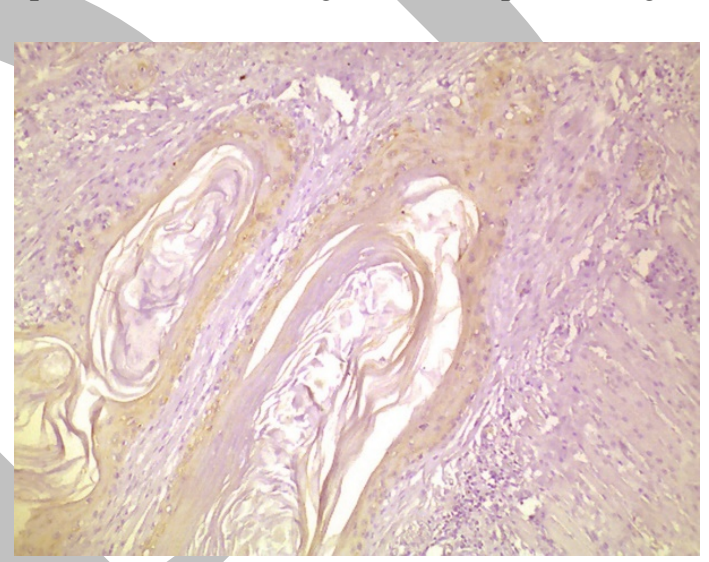

Figure 2: Well Differentiated Squamous Cell Carcinoma Showing Positive Cytoplasmic Immunosignaling of TLR-4 in The Malignant Epithelial Cells Forming the Keratin Pearls. (x400).

The Moderately differentiated OSCC showed positive strong cytoplasmic and membranous immunoreaction to TLR-4. Prominent nucleoli, abnormal mitosis figures and apoptotic cells were detected, (Figures 3 and 4).

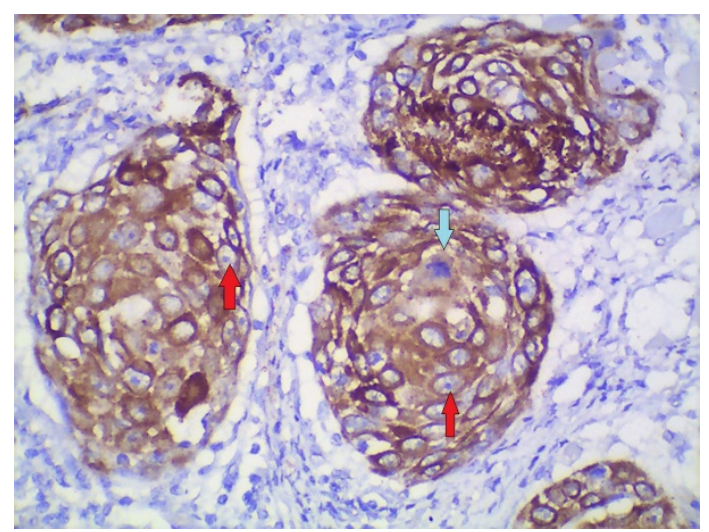

Figure 3: Moderately Differentiated Squamous Cell Carcinoma Showing Positive Strong Cytoplasmic Immunoreaction of TLR-4. Prominent Nucleoli are Noted (Red Arrows) Note the Abnormal Mitotic Figure (Blue arrow) (x400). 


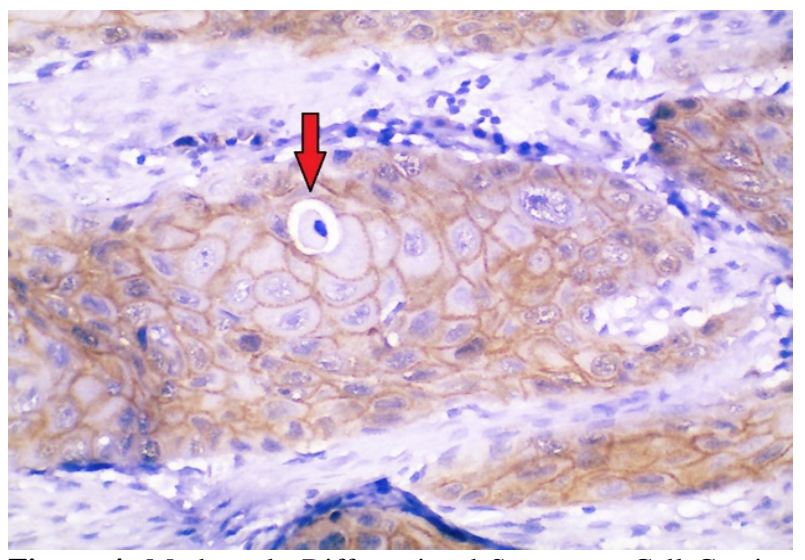

Figure 4: Moderately Differentiated Squamous Cell Carcinoma Exhibiting Membranous TLR-4 Immunosignals. The Nuclei are Devoid from Any Reaction. Note the Apoptotic cell (Red arrow) (x400).

In case of the poorly differentiated OSCC positive membranous and cytoplasmic immunosignals were detected in the highly anaplastic malignant epithelial cells. However, some malignant epithelial cells were devoid from any reaction (Figure 5).

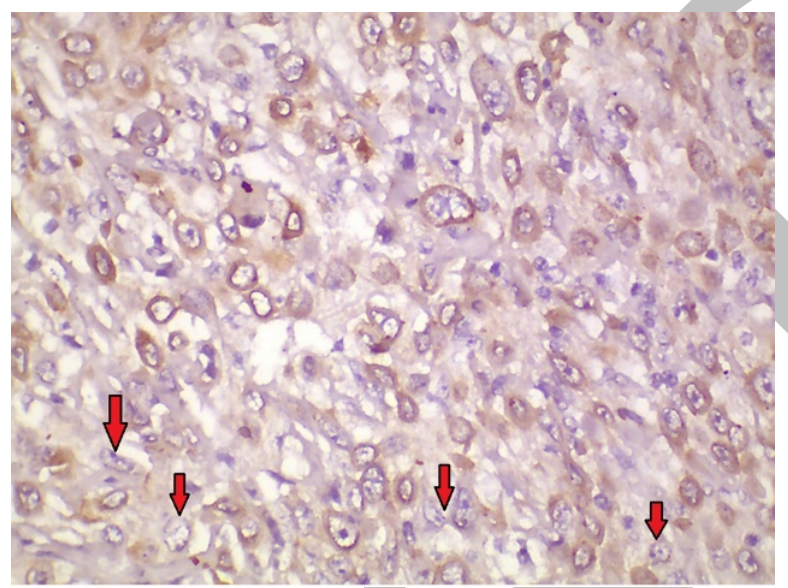

Figure 5: Poorly Differentiated Squamous Cell Carcinoma Revealing Positive Membranous and Cytoplasmic Immunosignals in the Anaplastic Epithelial Cells. Few Malignant Epithelial Cells are Negative (Arrows) (x400).

TLR-4 Immunoexpression in Correlation to the Histological Grading of OSCC:

Comparing the different grades of OSCC according to the area percent of TLR 4 immunoexpression, the greatest mean value was in the moderately differentiated squamous cell carcinoma (55.81 \pm 11.78 ), while the lowest value was detected in the poorly differentiated grade (13.89 \pm 7.38$)$ (Table 1). In regards to the optical density, the greatest mean value was detected in the moderately differentiated squamous cell carcinoma $(67.50 \pm 3.64)$ and the lowest value in the poorly differentiated OSCC $(25.14 \pm 4.41)$ (Table 2). The difference in the mean TLR-4 area percent and mean optical density between the different grades revealed statistical significance at $(\mathrm{P} \leq 0.05)$ (Figure 6).
Table (1): Comparison Between the Different Histological Grades of OSCC According to The Mean of the Area Percent of TLR 4 Receptor Immunoexpression

\begin{tabular}{|c|c|c|c|c|c||}
\hline $\begin{array}{c}\text { Mean of area } \\
\text { percent }\end{array}$ & $\begin{array}{c}\text { Well } \\
\text { differentia } \\
\text { ted OSCC }\end{array}$ & $\begin{array}{c}\text { Moderate } \\
\text { differentia } \\
\text { ted OSCC }\end{array}$ & $\begin{array}{c}\text { Poorly } \\
\text { differentia } \\
\text { ted OSCC }\end{array}$ & F & P \\
\hline Min. - & $18.31-$ & $27.81-$ & $1.10-$ & & \\
Max. & 56.25 & 78.64 & 19.61 & & \\
Mean \pm & $39.65 \pm$ & $55.81 \pm$ & $13.89 \pm$ & 32.02 & $<0.00$ \\
SD. & 12.44 & 11.78 & 7.38 & $0^{*}$ & $1^{*}$ \\
Median & 40.72 & 11.78 & 15.94 & & \\
\hline Sig. bet. grps. & $\mathrm{p}_{1}=0.002^{*}, \mathrm{p}_{2}=0.001^{*}, \mathrm{p}_{3}<0.001^{*}$ & & \\
\hline
\end{tabular}

F: F value for ANOVA test, pairwise comparison bet. each 2 groups were done using Post Hoc Test (Tukey)

$\mathrm{p}$ : $\mathrm{p}$ value for comparing between the different groups

$\mathrm{p}_{1}$ : p value for comparing between well differentiated SCC and moderate differentiated SCC

p2: p value for comparing between well differentiated SCC and poorly differentiated SCC

p3: p value for comparing between moderate differentiated SCC and poorly differentiated SCC

*: Statistically significant at $\mathrm{p} \leq 0.05$

Table (2): Comparison Between Different Histological Grades of OSCC According to The Mean of the Optical Density of TLR 4 Immunoexpression

\begin{tabular}{||c|c|c|c|c|c||}
\hline $\begin{array}{c}\text { Mean of } \\
\text { optical density }\end{array}$ & $\begin{array}{c}\text { Well } \\
\text { differentia } \\
\text { ted OSCC }\end{array}$ & $\begin{array}{c}\text { Moderate } \\
\text { differentia } \\
\text { ted OSCC }\end{array}$ & $\begin{array}{c}\text { Poorly } \\
\text { differentia } \\
\text { ted OSCC }\end{array}$ & F & p \\
\hline Min. - & $38.09-$ & $62.26-$ & $18.75-$ & & \\
Max. & 43.22 & 77.85 & 32.67 & & \\
Mean \pm & $39.70 \pm$ & $67.50 \pm$ & $25.14 \pm$ & 510.0 & $<0.00$ \\
SD. & 2.02 & 3.64 & 4.41 & $52^{*}$ & $1^{*}$ \\
Median & 39.14 & 67.36 & 25.55 & & \\
\hline Sig. bet. grps. & \multicolumn{2}{|c|}{$\mathrm{p}_{1}<0.001^{*}, \mathrm{p}_{2}<0.001^{*}, \mathrm{p}_{3}<0.001^{*}$} & & \\
\hline
\end{tabular}

F: F value for ANOVA test, pairwise comparison bet. each 2 groups were done using Post Hoc Test (Tukey)

$\mathrm{p}: \mathrm{p}$ value for comparing between the different groups

$\mathrm{p}_{1}$ : $\mathrm{p}$ value for comparing between well differentiated SCC and moderate differentiated SCC

p2: p value for comparing between well differentiated SCC and poorly differentiated SCC

p3: p value for comparing between moderate differentiated SCC and poorly differentiated SCC

$*$ : Statistically significant at $p \leq 0.05$ 


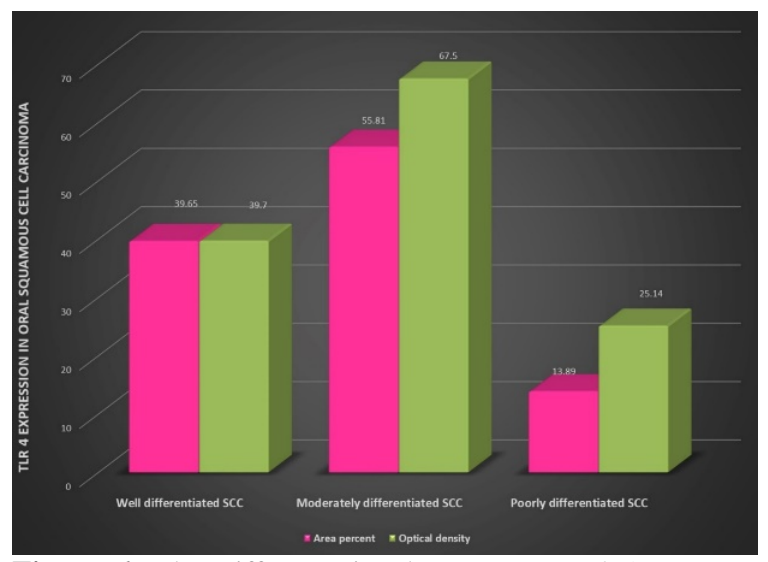

Figure 6: The Difference in The Mean TLR-4 Area Percent and Mean Optical Density Between the Different Grades of Oral Squamous cell carcinoma.

\section{DISCUSSION}

In Egypt, the relative incidence of oral cancer in 2015 was $0.9 \%$ in males and $0.75 \%$ in females (13). The prognosis of OSCC remains disgraceful as more than $50 \%$ of the patients die within 5 years due to the late diagnosis $(14,15)$. Therefore, an improved comprehension of the cellular and molecular mechanisms which initiate tumorigenesis or promote cancer progression has taken the center stage as a novel cancer treatment approach. Recently, there has been a growing recognition of interest in the anti-tumor functions initiated by the innate immune response. TLR stimulation in cancers have an anti- or pro-tumoral effect in the tumor microenvironment $(16,17)$.

The present study evaluated the possible relationship between the expression of TLR-4 in the tumor cells and the pathological characteristics in regards to the histological grade.

Squamous cell carcinoma cases included in the current research, showed that the lateral side of the tongue was the most prevalent site of occurrence followed by the buccal mucosa and the alveolar mucosa. This result is in accordance with many investigators who stated that the tongue was the most common site for squamous cell carcinoma (18-20). On the other hand, Effiom et al. (21) found that most of the examined OSCC cases were presented in the mandibular and maxillary alveolar ridge followed by the tongue. Moreover, Tandon et al. (22) have stated that the buccal mucosa is the most prevalent location for OSCC. This was attributed to the well-known habits of areca nut- and tobacco-chewing.

In the present research, all the control sections from the normal mucosa showed positive cytoplasmic TLR-4 immunosignals which were limited to the basal and the para basal cell layers. However, the cytoplasmic expression of TLR-4 in the control group was weaker than that seen in the tumor cells. This is in accordance with the findings reported by Kotrashetti et al. (23) which found that all the studied normal mucosa showed cytoplasmic immunosignals. Our results are also in consistent with Sugwara et al. (24) findings which showed that TLR-4 was expressed normally in the oral epithelial cells. They also indicated that these molecules in oral epithelial cells are functional receptors that induce antibacterial responses. Although Maikenin et al. (6) reported positive TLR4 expression, the staining pattern was different than our results. Their study showed positive nuclear immunostaining. On the other hand, Sun et al. (25) reported that TLR-4 was not expressed in the normal human oral cells. It seems that the difference in the results of many studies are likely to be that TLRs are mostly involved in ligand binding and they do not last long enough to stimulate the immune system. This may be because the basal epithelial layer, is found at the junction between the epithelium and the underlying lamina propria and could play a role in activating the humoral and cellular immune systems. Therefore, this specific basal layer acts as a barrier if the outermost layers are not stimulated (26).

In the current work, TLR-4 immunoexpression was evaluated using the image analyzer. All the examined OSCC cases revealed positive expression, that was observed in the cytoplasm as well as the membrane of the malignant epithelial cells. Our examined cases (moderate and well differentiated types) showed higher statistically significant expression of TLR-4 than the poorly differentiated grade. This is in accordance with Sun et al. (25). They observed high expression of TLR-4 in the well and the moderately differentiated types, whereas it was weak in the poorly differentiated tumors. Furthermore, this agrees with Kotrashetti et al. (23) study which reported that TLR-4 is highly expressed in the welldifferentiated carcinomas, and the expression level is closely associated with the degree of oral epithelial dysplasia and the distribution of cancer cells. Moreover, Maikenin et al (27) and Pakdel et al (28) investigations revealed that TLR-4 was expressed in all the primary, recurrent and metastatic tumors of OSCC. However, Park et al. (29) investigated the expression of TLR 2, 3, 4, .5, 7 and 9 in OSCC cell lines and on tissue sections, and found high expression of TLR5,7,9 and weak expression of TLR 2,3,4. In addition, Rydberg et al. (30) studied various types of TLR in head and neck squamous cell carcinoma cell lines; and they barely detected TLR-4 expression.

The difference in the expression patterns also varies greatly according to the physiological or pathological conditions prevailing in the host system. Variation in TLR expression can be explained by two mechanisms (9). Upregulation of TLRs can be of a great benefit to the tumor owing to its anti-apoptotic activity, which permits the tumor cell survival. In addition, TLR may help the immune system to act as a defensive mechanism against the malignant transformation of the cells. Therefore, TLR agonists frequently have been used as immune adjuvants in anticancer immunotherapy $(31,32)$.

\section{CONCLUSION}

TLR-4 expression could be a prognostic factor in oral squamous cell carcinoma cases since its expression was detected in the moderately and the well differentiated more than the poorly differentiated squamous cell carcinoma.

\section{CONFLICT OF INTEREST}

The authors declare that they have no conflicts of interest.

\section{REFERENCES}

1. Bray F, Ferlay J, Laversanne M, Brewster DH, Gombe Mbalawa C, Kohler B, et al. Cancer Incidence in Five Continents: Inclusion criteria, highlights from Volume $\mathrm{X}$ and the global status of cancer registration. International journal of cancer. 2015;137:2060-71.

2. Omar K, Camile SF, Newell WJ. Oral and oropharyngeal cancer in the Middle East and North Africa: Incidence, 
mortality, trends, and gaps in public databases as presented to the Global Oral Cancer Forum. Translational Research in Oral Oncology. 2017;2:2057178X17698480.

3. Choi S, Myers JN. Molecular pathogenesis of oral squamous cell carcinoma: implications for therapy. Journal of dental research. 2008;87:14-32.

4. Akira S, Takeda K. Toll-like receptor signalling. Nature Reviews Immunology. 2004;4:499.

5. Rich AM, Hussaini HM, Parachuru VPB, Seymour GJ. Toll-Like Receptors and Cancer, Particularly Oral Squamous Cell Carcinoma. Frontiers in Immunology. 2014;5:464.

6. Makinen LK, Atula T, Hayry V, Jouhi L, Datta N, Lehtonen S, et al. Predictive role of Toll-like receptors 2, 4 , and 9 in oral tongue squamous cell carcinoma. Oral Oncol. 2015;51:96-102.

7. Mai CW, Kang YB, Pichika MR. Should a Toll-like receptor 4 (TLR-4) agonist or antagonist be designed to treat cancer? TLR-4: its expression and effects in the ten most common cancers. OncoTargets and therapy. 2013;6:1573-87.

8. Sato Y, Goto Y, Narita N, Hoon DSB. Cancer Cells Expressing Toll-like Receptors and the Tumor Microenvironment. Cancer Microenvironment. 2009;2:205-14.

9. Vidya MK, Kumar VG, Sejian V, Bagath M, Krishnan G, Bhatta R. Toll-like receptors: Significance, ligands, signaling pathways, and functions in mammals. International Reviews of Immunology. 2018;37:20-36.

10. Syrbu SI, Cohen MB. An enhanced antigen-retrieval protocol for immunohistochemical staining of formalinfixed, paraffin-embedded tissues. Methods Mol Biol. 2011;717:101-10.

11. Kotz S, Balakrishnan N, Read CB, Vidakovic B. Encyclopedia of statistical sciences. 2nd ed. Hoboken, N.J.: Wiley-Interscience; 2006.

12. Kirkpatrick LA, Feeney BC. A simple guide to IBM SPSS statistics for version 20.0. Student ed. Belmont, Calif.: Wadsworth, Cengage Learning; 2013

13. Ibrahim AS, Khaled HM, Mikhail NN, Baraka H, Kamel $\mathrm{H}$. Cancer incidence in Egypt: Results of the national population-based cancer registry program. J Cancer Epidemiol. 2014;2014:1-18.

14. Markopoulos AK. Current Aspects on Oral Squamous Cell Carcinoma. The Open Dentistry Journal. 2012;6:126-30.

15. Scott SE, Grunfeld EA, Main J, McGurk M. Patient delay in oral cancer: a qualitative study of patients' experiences. Psycho-oncology. 2006;15:474-85.

16. Dajon M, Iribarren K, Cremer I. Dual roles of TLR7 in the lung cancer microenvironment. OncoImmunology. 2015;4:e991615.

17.Dajon M, Iribarren K, Cremer I. Toll-like receptor stimulation in cancer: A pro- and anti-tumor double-edged sword. Immunobiology. 2017;222:89-100.

18. van Zyl A, Bunn B. Clinical features of oral cancer. SADJ. 2012;67:566-9.

19. Mesquita JA, Cavalvanti AL, Nonaka CFW, Godoy GP, Alves PM. Clinical and histopathological evidence of oral squamous cell carcinoma in young patients : systematized review. J Bras Patol Med Lab. 2014;50:67-74.

20. Pires FR, Ramos AB, de Oliveira JBC, Tavares AS, da Luz PSR, dos Santos TCRB. Oral squamous cell carcinoma: clinicopathological features from 346 cases from a single
Oral Pathology service during an 8-year period. J Appl Oral Sci. 2013;21:460-7.

21. Effiom OA, Adeyemo WL, Omitola OG, Ajayi OF, Emmanuel MM, Gbotolorun OM. Oral squamous cell carcinoma: a clinicopathologic review of 233 cases in Lagos, Nigeria. J Oral Maxillofac Surg. 2008;66:1595-9.

22. Tandon P, Dadhich A, Saluja H, Bawane S, Sachdeva S. The prevalence of squamous cell carcinoma in different sites of oral cavity at our Rural Health Care Centre in Loni, Maharashtra - a retrospective 10-year study. Contemp Oncol. 2017;21:178-83.

23. Kotrashetti VS, Nayak R, Bhat K, Hosmani J, Somannavar P. Immunohistochemical expression of TLR4 and TLR9 in various grades of oral epithelial dysplasia and squamous cell carcinoma, and their roles in tumor progression: a pilot study. Biotechnic \& histochemistry : official publication of the Biological Stain Commission. 2013;88:311-22.

24. Sugawara Y, Uehara A, Fujimoto Y, Kusumoto S, Fukase K, Shibata K, et al. Toll-like receptors, NOD1, and NOD2 in oral epithelial cells. Journal of dental research. 2006;85:524-9.

25. Sun Z, Luo Q, Ye D, Chen W, Chen F. Role of toll-like receptor 4 on the immune escape of human oral squamous cell carcinoma and resistance of cisplatin-induced apoptosis. Molecular cancer. 2012;11:33-.

26. Ali A, Natah S, Konttinen Y. Differential expression of Toll-like receptors in chronic hyperplastic candidosis. Oral microbiology and immunology. 2008;23:299-307.

27. Makinen LK, Ahmed A, Hagstrom J, Lehtonen S, Makitie AA, Salo T, et al. Toll-like receptors 2, 4, and 9 in primary, metastasized, and recurrent oral tongue squamous cell carcinomas. Journal of oral pathology \& medicine : official publication of the International Association of Oral Pathologists and the American Academy of Oral Pathology. 2016;45:338-45.

28. Pakdel F , Pouralibaba F , Pakdel S , Khiyavi RK , Falsafi $\mathrm{P}$, Eslami $\mathrm{H}$, et al. Expression of toll-like receptors in squamous cell csrcinoma of the tongue. Archives of Applied Science Research. 2015; 7:20-24

29. Park J-H, Yoon H-E, Jeon D-I, Ahn S-G, Yoon J-H. Activation of TLR2 and TLR5 did not affect tumor progression of an oral squamous cell carcinoma, YD-10B cells. Journal of Oral Pathology \& Medicine. 2010;39:7815.

30. Rydberg C, Månsson A, Uddman R, Riesbeck K, Cardell L-O. Toll-like receptor agonists induce inflammation and cell death in a model of head and neck squamous cell carcinomas. Immunology. 2009;128:e600-e11.

31. Du B, Jiang Q-L, Cleveland J, Liu B-R, Zhang D. Targeting Toll-like receptors against cancer. Journal of Cancer Metastasis and Treatment. 2016;2:463-70.

32. Huang L, Xu H, Peng G. TLR-mediated metabolic reprogramming in the tumor microenvironment: potential novel strategies for cancer immunotherapy. Cellular And Molecular Immunology. 2018. 